\title{
Upregulation of long non-coding RNA urothelial carcinoma associated 1 by CCAAT/enhancer binding protein $\alpha$ contributes to bladder cancer cell growth and reduced apoptosis
}

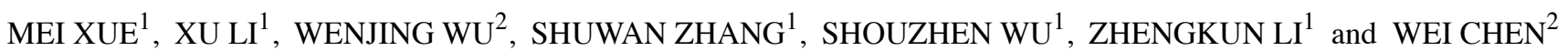 \\ ${ }^{1}$ Center for Translational Medicine, and ${ }^{2}$ Clinical Laboratory, The First Affiliated Hospital, \\ School of Medicine, Xi'an Jiaotong University, Xi'an 710061, P.R. China
}

Received January 20, 2014; Accepted March 6, 2014

DOI: $10.3892 /$ or.2014.3092

\begin{abstract}
Long non-coding RNA urothelial carcinoma associated 1 (IncRNA-UCA1) is upregulated in bladder cancer and plays a pivotal role in bladder cancer progression and metastasis. Recent studies and our research found that IncRNA-UCA1 may be an important biomarker and therapeutic target for bladder cancer. However, the molecular mechanism involved in the upregulation of IncRNA-UCA1 in bladder cancer is largely unknown. In the present study, we showed that IncRNA-UCA1 expression in bladder cancer cells was upregulated by transcription factor CCAAT/enhancer binding protein $\alpha(\mathrm{C} / \mathrm{EBP} \alpha)$, which was the only candidate transcription factor simultaneously predicted by a total of five bioinformatical software programs. Electrophoretic mobility shift assay and chromatin immunoprecipitation assay indicated that $\mathrm{C} / \mathrm{EBP} \alpha$ bound to the IncRNA-UCA1 core promoter region in vitro and in vivo. The luciferase assays further showed that there was a point mutation (A231G) in the $\mathrm{C} / \mathrm{EBP} \alpha$ binding site of the IncRNA-UCA1 core promoter in various bladder cancer cell lines, which in turn significantly increased the transcriptional activity of IncRNA-UCA1. We also demonstrated that $\mathrm{C} / \mathrm{EBP} \alpha$ siRNA treatment contributed to the downregulation of IncRNA-UCA1 expression, whereas overexpression of C/EBP $\alpha$ enhanced lncRNA-UCA1 expression. Furthermore, IncRNA-UCA1 transcriptional repression by C/EBP $\alpha$ siRNA sharply reduced cell viability and induced cell apoptosis in vitro. Collectively, our results provide a novel therapeutic strategy for bladder cancer by effectively interrupting the binding of the IncRNA-UCA1 promoter and certain transcription factors, so as to reverse the upregulation of IncRNA-UCA1 and prevent bladder cancer progression.
\end{abstract}

Correspondence to: Professor Wei Chen, Clinical Laboratory, The First Affiliated Hospital, School of Medicine, Xi'an Jiaotong University, Xi'an 710061, P.R. China

E-mail: chenwei2011xjtu@gmail.com

Key words: long non-coding RNA, urothelial carcinoma associated 1, bladder cancer, transcription factor, CCAAT/enhancer binding protein $\alpha$

\section{Introduction}

Bladder cancer is the most common malignancy in the male urinary system. In the United States, 72,570 new cases and 15,210 deaths from bladder cancer were estimated to occur in 2013 (1). Despite advances in surgical and chemical therapies, the high incidence of metastasis and recurrence accounts for the main cause of bladder cancer mortality (2). Therefore, efforts in exploring molecular markers and therapeutic targets against metastasis and relapse of bladder carcinoma are of particular significance (3). Long non-coding RNAs (lncRNAs, $>200$ nucleotides), a huge body of emerging transcripts incapable of coding proteins yet exhibiting multiple regulatory functions, have gained increasing attention in the field of molecular biology and have been found to be involved in diverse essential bioactivities including cell proliferation and apoptosis (4-6). A large number of complex human diseases, particularly cancers, are accompanied by abnormal lncRNA expression and consequent dysfunction (7). Previous research has shown that certain lncRNAs can be applied as novel biomarkers and targets for cancer detection and treatment (8).

Long non-coding RNA urothelial carcinoma associated 1 (lncRNA-UCA1) is a highly specific lncRNA exclusively expressed in bladder cancer, with significantly higher expression in bladder cancer tissues when compared with that in adjacent normal tissues (9). Detection of lncRNA-UCA1 in urine sediment has proven to be highly sensitive and specific for diagnosing bladder carcinoma. Ectopic lncRNA-UCA1 expression promotes the proliferation, motility, invasion and drug resistance of bladder cancer cells (10-12). Taken together, IncRNA-UCA1 is a potential biomarker for bladder cancer diagnosis and prognosis (13). However, the mechanism underlying the upregulation of IncRNA-UCA1 expression in bladder cancer remains to be elucidated. Although the biological origins of lncRNAs are extremely complicated, their transcriptional regulation and post-transcriptional processing are similar to those of protein-coding genes. A number of studies concerning the transcriptional regulation of lncRNAs indicate that transcription factors regulate lncRNAs mainly by binding with their promoters $(14,15)$. Both lncRNAs and protein-coding genes are regulated by classic transcriptional regulatory proteins. 
In the present study, we aimed to elucidate the mechanism underlying the upregulation of IncRNA-UCA1 in bladder cancer cells. We demonstrated that CCAAT/enhancer binding protein $\alpha(\mathrm{C} / \mathrm{EBP} \alpha)$ binds to the core promoter region of lncRNA-UCA1 in vitro and in vivo. When the expression of IncRNA-UCA1 is upregulated by $\mathrm{C} / \mathrm{EBP} \alpha$, it contributes to increased cell viability and reduced cell apoptosis in vitro. Our results, therefore, demonstrate a regulatory mechanism for IncRNA-UCA1 upregulation in bladder cancer cells. Knowledge of the mechanism involved in the upregulation of IncRNA-UCA1 will be of huge benefit for both basic research and therapeutic application in human bladder cancer.

\section{Materials and methods}

Cell culture and siRNA transfection. The human bladder cancer cell lines 5637 and T24 were obtained from the American Type Culture Collection (ATCC; Manassas, VA, USA). The human bladder cancer cell lines BLZ-211 and BLS-211 are described elsewhere (16). The cells were grown in RPMI-1640 (Gibco, Gaithersburg, MD, USA) with $10 \%$ bovine calf serum. The cultures were maintained at $37^{\circ} \mathrm{C}$ under a humidified $5 \%$ $\mathrm{CO}_{2}$ atmosphere. $\mathrm{C} / \mathrm{EBP} \alpha$ siRNA was transiently transfected into bladder cancer cell lines using X-tremeGENE siRNA transfection reagent (Roche Diagnostics, Indianapolis, IN, USA). Following $48 \mathrm{~h}$ of $\mathrm{C} / \mathrm{EBP} \alpha$ siRNA transfection, the cells were harvested for further studies. C/EBP $\alpha$ siRNAs (Shanghai Genepharma Co., Ltd., Shanghai, China) are listed in Table I.

Transcription factor predictions. Transcription factor predictions were carried out using AliBaba (http://www. gene-regulation.com/pub/programs.html\#alibaba2), Matrix Catch (http://www.gene-regulation.com/pub/programs. html\#mcatch), TESS (http://www.cbil.upenn.edu/tess), TFSEARCH (http://www.cbrc.jp/research/db/TFSEARCH. html) and Patch (http://www.gene-regulation.com/pub/ programs.html\#patch) software programs with the default parameter values. The motifs of transcription factor $\mathrm{C} / \mathrm{EBP} \alpha$ that bind with the IncRNA-UCA1 promoter were determined according to JASPAR (http://jaspar.cgb.ki.se) database matrix information.

Electrophoretic mobility shift assay (EMSA). The nuclear proteins of bladder cancer cells were prepared using NE-PER nuclear and cytoplasmic extraction reagents (Pierce, Rockford, IL, USA). EMSA was carried out using a LightShift chemiluminescent EMSA kit (Pierce). The probes are listed in Table I.

Chromatin immunoprecipitation assay (ChIP). ChIP was performed using an EZ-ChIP chromatin immunoprecipitation kit (Millipore, Bedford, MA, USA). Chromatin was immunoprecipitated using anti- $\mathrm{C} / \mathrm{EBP} \alpha$ antibodies (Abcam, Cambridge, MA, USA). Human IgG was used as the negative control. The precipitated DNA was monitored by PCR using specific primers for the lncRNA-UCA1 promoter. The primers are listed in Table I.

Quantitative real-time PCR. Total RNA was extracted from bladder cancer cell lines using TRIzol reagent (Invitrogen, Carlsbad, CA, USA). First-strand cDNA was synthesized using the PrimeScript RT reagent kit (Perfect Real-Time; Takara, Dalian, China). Quantitative real-time PCR was carried out using a SYBR Premix Ex Taq ${ }^{\mathrm{TM}}$ II (Takara) on a CFX96 real-time PCR system (Bio-Rad Laboratories, Hercules, CA, USA), and the results were normalized to $\beta$-actin as an internal control. The primers are listed in Table I.

Plasmid constructs and transient transfection. The IncRNAUCA1 promoter reporter constructs were obtained by PCR. The PCR products were digested and ligated into pGL3 basic vector. The $\mathrm{C} / \mathrm{EBP} \alpha$ binding site mutation was generated using a QuickChange Multi Site-Directed Mutagenesis kit (Stratagene, La Jolla, CA, USA). The IncRNA-UCA1 promoter reporter plasmid was used as the template. The mutant primers are listed in Table I. The human pGV219-C/EBP $\alpha$ expression vectors and empty vectors (GV219) were obtained from Shanghai Genechem Co., Ltd. (Shanghai, China). Bladder cancer cells were transiently transfected with a pGV219-C/EBP $\alpha$ or empty vector (GV219) as a control using the X-tremeGENE HP DNA transfection reagent (Roche). After $48 \mathrm{~h}$ of transfection, the cells were harvested for further studies.

Luciferase reporter assay. Transient transfection of the lncRNA-UCA1 promoter reporter plasmid and the internal control Renilla luciferase plasmid was carried out with the X-tremeGENE HP DNA transfection reagent. After $48 \mathrm{~h}$ of transfection, luciferase activity was measured using a dualluciferase reporter gene assay system (Promega, Madison, WI, USA).

MTT assay. The cells were transfected with $\mathrm{C} / \mathrm{EBP} \alpha$ siRNA. Every day until day 6, MTT (Amresco, Solon, OH, USA) was added to each well, and incubation was carried out at $37^{\circ} \mathrm{C}$ for $4 \mathrm{~h}$. The medium was removed and DMSO was added into each well. Absorbance was measured at $490 \mathrm{~nm}$.

Cell apoptosis assay. After $48 \mathrm{~h}$ of treatment with $\mathrm{C} / \mathrm{EBP} \alpha$ siRNA, the cells were stained with Annexin V-FITC and propidium iodide (Beyotime Institute of Biotechnology, Haimen, China) and examined using a flow cytometer (FACS; BD Biosciences, Sparks, MD, USA).

Statistical analysis. All the experiments were performed at least in triplicate. Data are presented as means \pm SEM, and were analyzed using the SPSS 19.0 and Graphpad Prism 5. Statistical analyses were carrried out using a two-tailed unpaired Student's t-test. Differences with $\mathrm{P}<0.05$ were considered statistically significant.

\section{Results}

Bioinformatic analysis of the IncRNA-UCAl core promoter region. In our previous study, we confirmed that the IncRNAUCA1 promoter was located at the 5' end of the IncRNA-UCA1 gene, from $-1800 \mathrm{bp}$ to $+200 \mathrm{bp}$, with the core promoter ranging from $-400 \mathrm{bp}$ to $-150 \mathrm{bp}$ (17). Several potential transcription factor binding sites were predicted in the lncRNA-UCA1 core promoter region. $\mathrm{C} / \mathrm{EBP} \alpha$ was the only candidate transcription factor predicted by five bioinformatical software programs simultaneously (Table II). It was further speculated that there 
Table I. Primer, probe and siRNA list.

\begin{tabular}{|c|c|c|}
\hline mRNA/gene promoter & Sequence $\left(5^{\prime}-3^{\prime}\right)$ & Experimental use \\
\hline UCA1 & $\begin{array}{l}\text { CTCTCCATTGGGTTCACCATTC } \\
\text { GCGGCAGGTCTTAAGAGATGAG }\end{array}$ & Real-time PCR \\
\hline $\mathrm{C} / \mathrm{EBP} \alpha$ & $\begin{array}{l}\text { ATTGGAGCGGTGAGTTTG } \\
\text { TTGGTGCGTCTAAGATGAG }\end{array}$ & Real-time PCR \\
\hline$\beta$-actin & $\begin{array}{l}\text { TCCCTGGAGAAGAGCTACGA } \\
\text { AGCACTGTGTTGGCGTACAG }\end{array}$ & Real-time PCR \\
\hline UCA1 promoter $(\mathrm{C} / \mathrm{EBP} \alpha)$ & $\begin{array}{l}\text { TCTCAGGCTGTCCTCTGGGAAG } \\
\text { TGTAGGCCACCTGGACATATATGTG }\end{array}$ & ChIP-PCR \\
\hline UCA1 promoter $(\mathrm{C} / \mathrm{EBP} \alpha)$ & $\begin{array}{l}\text { CATCACCCTGTAACAGGGAACTGTCAGG } \\
\text { CCTGACAGTTCCCTGTTACAGGGTGATG }\end{array}$ & Site-directed mutagenesis \\
\hline UCA1 promoter (A231G) & $\begin{array}{l}\text { CCCTGTAACGTTTCCAGAAGGGAACTGTCAGG } \\
\text { CCTGACAGTTCCCTTCTGGAAACGTTACAGGG }\end{array}$ & Site-directed mutagenesis \\
\hline $\mathrm{C} / \mathrm{EBP} \alpha$ probe & $\begin{array}{l}\text { CAGTTCCCTTTGGAAACGTTACAGGG } \\
\text { CCCTGTAACGTTTCCAAAAGGGAACTG }\end{array}$ & EMSA \\
\hline $\mathrm{C} / \mathrm{EBP} \alpha$ mutant probe & $\begin{array}{l}\text { CAGTTCCCTAACTTGAGCGTTACAGGG } \\
\text { CCCTGTAACGCTCAAGTTAGGGAACTG }\end{array}$ & EMSA \\
\hline siRNA control & $\begin{array}{l}\text { UUCUCCGAACGUGUCACGUTT } \\
\text { ACGUGACACGUUCGGAGAATT }\end{array}$ & RNA interference \\
\hline $\mathrm{C} / \mathrm{EBP} \alpha$ siRNA & $\begin{array}{l}\text { ACGAGACGUCCAUCGACAUTT } \\
\text { AUGUCGAUGGACGUCUCGUTT }\end{array}$ & RNA interference \\
\hline
\end{tabular}

Table II. Bioinformatic software programs predicting the transcription factors that bind with the lncRNA-UCA1 core promoter region.

Transcription factors

$\mathrm{C} / \mathrm{EBP} \alpha(\mathrm{CCAAT} / \mathrm{enhancer}$ binding protein $\alpha)$

CREB (cAMP responsive element binding protein)

GATA-1 (globin transcription factor 1)

c-MYB (myelocytomatosis viral oncogene homolog)

SP1 (sequence-specific transcription factor 1)
Bioinformatic software programs

Predicted results

+ , indicates the number of programs that predicted this transcription factor.

were more than one putative $\mathrm{C} / \mathrm{EBP} \alpha$ binding site in the lncRNA-UCA1 core promoter region (Table III). Based on the JASPAR database, we determined that a unique motif of $\mathrm{C} / \mathrm{EBP} \alpha$ (from $-239 \mathrm{bp}$ to $-230 \mathrm{bp}$, GTTTCCAAA) was potentially eligible to interact and bind with the lncRNA-UCA1 core promoter (Fig. 1A and B). In order to screen out a perfect cell model by which to validate our prediction results, we detected the constitutive expression of $\mathrm{C} / \mathrm{EBP} \alpha$ and lncRNAUCA1 in three bladder cancer cell lines. As shown in Fig. 1C, $\mathrm{C} / \mathrm{EBP} \alpha$ was expressed in all of the three bladder cell lines. lncRNA-UCA1 expression was high in the cell line BLZ-211, yet extremely low, if not absent, in its counterpart cell line BLS-211, although the two cell lines were derived from the same patient (16). Therefore, BLS-211 was employed as the control cell line in the subsequent experiments.
$C / E B P \alpha$ binds to the IncRNA-UCAl core promoter. To confirm whether $\mathrm{C} / \mathrm{EBP} \alpha$ binds to the IncRNA-UCA1 core promoter region, we performed an electrophoretic mobility shift assay (EMSA) using biotin-labeled DNA probes with $\mathrm{C} / \mathrm{EBP} \alpha$ binding site sequences. The complexes of nucleoprotein and biotin-labeled DNA probes were detected in all the three cell lines, BLZ-211, 5637 and T24. However, no complexes in the control group with cold probes (unlabeled probes) competing with the biotin-labeled DNA probes were detected in the three cell lines. Furthermore, the mutant probes $(\mathrm{C} / \mathrm{EBP} \alpha$ binding sites mutant) were unable to competitively inhibit the formation of the complex bands and thus complexes were also detected in this group (Fig. 2A). Together, these results suggest that $\mathrm{C} / \mathrm{EBP} \alpha$ specifically interacts and binds with the IncRNAUCA1 core promoter in vitro. 
Table III. Bioinformatic software programs predicting the $\mathrm{C} / \mathrm{EBP} \alpha$ binding sites in the lncRNA-UCA1 core promoter region.

\begin{tabular}{lcll}
\hline $\begin{array}{l}\text { Bioinformatic } \\
\text { software }\end{array}$ & $\begin{array}{c}\text { Number of C/EBP } \alpha \\
\text { binding sites }\end{array}$ & Position (strand) & Matrix sequence \\
\hline AliBaba & Three binding sites & $-335 \mathrm{bp}-326 \mathrm{bp}(+)$ & GCAGCTTGTG \\
& & $-282 \mathrm{bp}-273 \mathrm{bp}(+)$ & GGAAAAGATA \\
& & $-264 \mathrm{bp}-255 \mathrm{bp}(+)$ & GGCTGAGGTC \\
MatrixCatch & One binding site & $-303 \mathrm{bp}-277 \mathrm{bp}(+)$ & CAGTTCTGAAACCAGGACCAGGAAAA \\
Patch & Two binding sites & $-302 \mathrm{bp}-294 \mathrm{bp}(-)$ & TTCAGAAAT \\
& & $-238 \mathrm{bp}-233 \mathrm{bp}(+)$ & TTTCCA \\
TESS & Two binding sites & $-301 \mathrm{bp}-292 \mathrm{bp}(+)$ & GTTCTGAAAC \\
& & $-238 \mathrm{bp}-229 \mathrm{bp}(+)$ & TTTCCAAAA \\
TFSEARCH & One binding site & $-241 \mathrm{bp}-228 \mathrm{bp}(+)$ & ACGTTTCCAAAAG \\
\hline
\end{tabular}

A

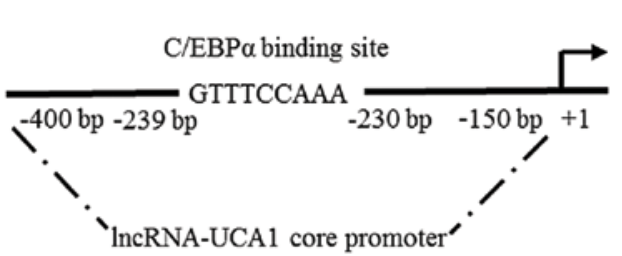

B
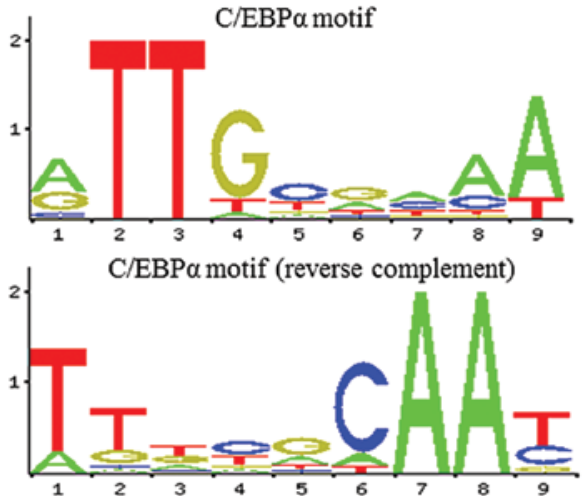

$\mathrm{C}$
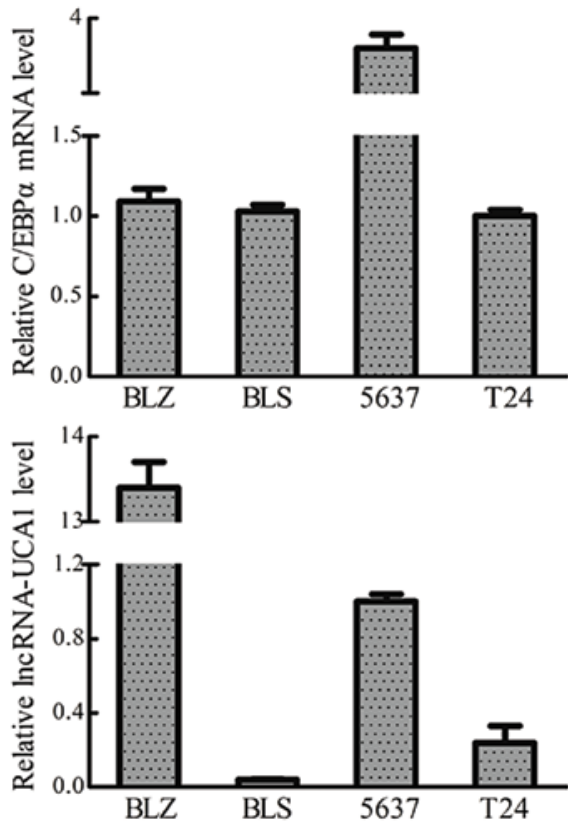

Figure 1. Bioinformatic analysis of the lncRNA-UCA1 core promoter region. (A) Schematic representation of the putative C/EBP $\alpha$ binding site in the lncRNAUCA1 core promoter. (B) Sequence logo of C/EBP $\alpha$ was obtained from the JASPAR database. (C) C/EBP $\alpha$ and lncRNA-UCA1 expression levels were analyzed in the various cell lines by real-time PCR. $\beta$-actin was used as the internal control.

We then performed ChIP experiments to further confirm the binding of $\mathrm{C} / \mathrm{EBP} \alpha$ to the lncRNA-UCA1 core promoter in vivo. As shown in Fig. $2 \mathrm{~B}, \mathrm{C} / \mathrm{EBP} \alpha$ was able to bind to the $\mathrm{C} / \mathrm{EBP} \alpha$ binding site $(-239 \mathrm{bp}$ to $-230 \mathrm{bp}$ ) of the IncRNAUCA1 core promoter in the BLZ-211, 5637 and T24 cells. Importantly, a base transversion (A231G) of the C/EBP $\alpha$ binding site sequence was found in the T24 cells (Fig. 2C). We then aimed to ascertain whether this point mutation affects the binding activity between $\mathrm{C} / \mathrm{EBP} \alpha$ and the lncRNA-UCA1 promoter. Thus, we were motivated to establish lncRNA-UCA1 promoter constructs with mutant (231G) and wild-type (231A) $\mathrm{C} / \mathrm{EBP} \alpha$ binding sites. The luciferase assay demonstrated that the mutant $\mathrm{C} / \mathrm{EBP} \alpha$ binding site $(231 \mathrm{G})$ had an increase in luciferase activity, when compared with that of the wild-type (231A) in all cell lines ( 2-fold; Fig. 3A). Collectively, these data indicate that $\mathrm{C} / \mathrm{EBP} \alpha$ binds with the lncRNA-UCA1 core promoter in vitro and in vivo.

$C / E B P \alpha$ regulates $\ln C R N A-U C A 1$ expression. To verify whether $\mathrm{C} / \mathrm{EBP} \alpha$ regulates 1 cRNA-UCA1 transcription in bladder cancer cells, a C/EBP $\alpha$ binding site deleted lncRNA-UCA1 promoter construct (mutant) was cloned. The cells transfected with the mutant promoter construct displayed a $\sim 30 \%$ reduction in luciferase reporter activities (Fig. 3B). Therefore, the $\mathrm{C} / \mathrm{EBP} \alpha$ binding site contributes to IncRNA-UCA1 transcriptional activation. BLZ-211, 5637 and T24 cells were transfected with $\mathrm{C} / \mathrm{EBP} \alpha$ siRNA. The $\mathrm{C} / \mathrm{EBP} \alpha \mathrm{mRNA}$ and protein levels were reduced by $\sim 70$ and $\sim 50 \%$, respectively (Fig. $4 \mathrm{~A}$ and B). Silencing of $\mathrm{C} / \mathrm{EBP} \alpha$ also reduced lncRNA-UCA1 promoter activities (30-50\% reduction) and expression levels (30-50\% 
A

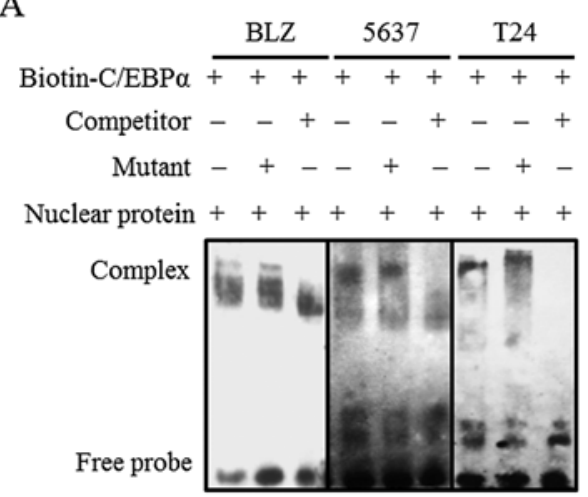

B
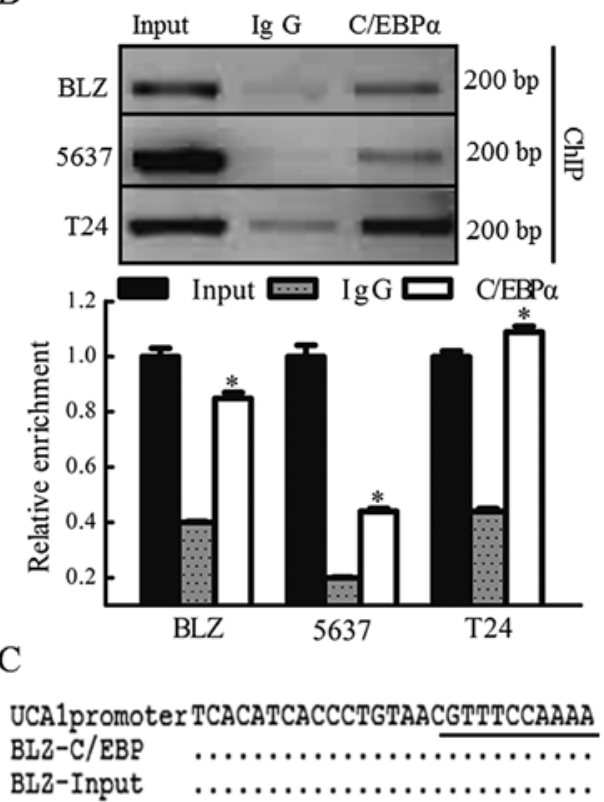

UCA1promoter TCACATCACCCTGTAACGTITCCAAAA

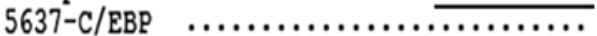

5637-Input $\ldots \ldots \ldots \ldots \ldots \ldots \ldots \ldots \ldots \ldots$

UCA1promoter TCACATCACCCTGTAACGTTTCCAAAA

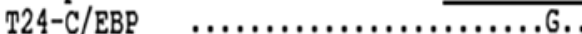

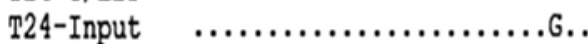

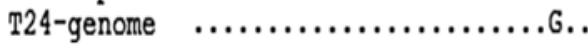

Figure 2. C/EBP $\alpha$ binds with the lncRNA-UCA1 core promoter. (A) EMSA indicates the interaction of $\mathrm{C} / \mathrm{EBP} \alpha$ with the lncRNA-UCA1 core promoter in vitro. (B) ChIP indicates the interaction of $\mathrm{C} / \mathrm{EBP} \alpha$ with the lncRNAUCA1 core promoter in vivo $\left({ }^{*} \mathrm{P}<0.05 ; \mathrm{n}=3\right)$. (C) $\mathrm{PCR}$ products from the ChIP were sequenced. The sequences were aligned using BioEdit.

reduction) in the BLZ-211, 5637 and T24 cells (Fig. 4C and D), while overexpression of C/EBP $\alpha$ in the 5637 and T24 cells led to an increase in $\mathrm{C} / \mathrm{EBP} \alpha$ protein levels ( 1.65 -fold; Fig. $5 \mathrm{~A})$, followed by increases in IncRNA-UCA1 promoter activity $(\sim 2.5$-fold; Fig. 5B) and expression levels ( 3 -fold; Fig. 5C), respectively. Taken together, these results indicate that $\mathrm{C} / \mathrm{EBP} \alpha$ strengthens lncRNA-UCA1 transcription.

$C / E B P \alpha$ regulates IncRNA-UCA1 expression to increase cell viability and reduce cell apoptosis. To determine whether transcriptional inhibition of lncRNA-UCA1 affects its biological function, we measured cell viability using MTT
A

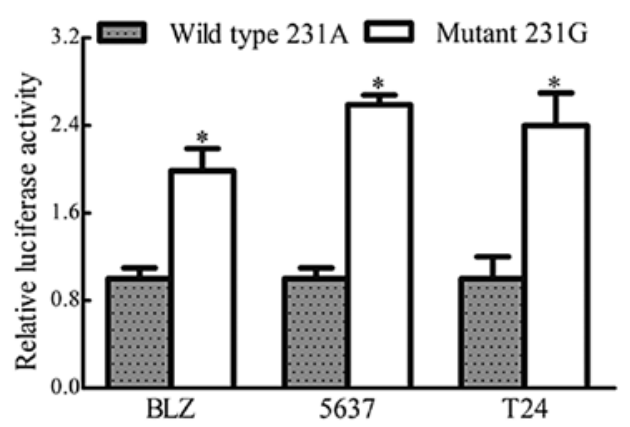

B

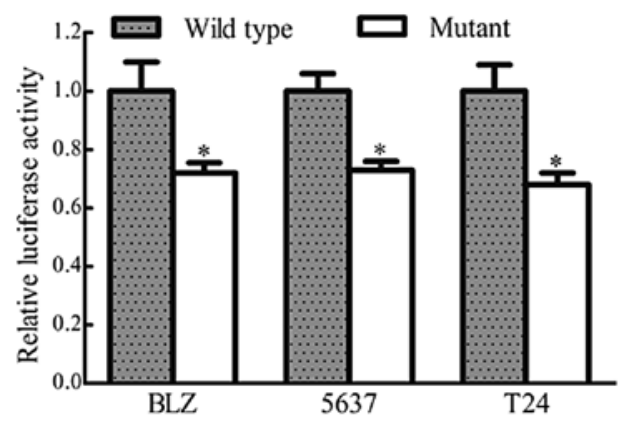

Figure 3. $\mathrm{C} / \mathrm{EBP} \alpha$ binding site contributes to lncRNA-UCA1 transcriptional activation. (A) Bladder cancer cells were transfected with $\mathrm{C} / \mathrm{EBP} \alpha$ binding site mutant (231G) lncRNA-UCA1 promoter constructs. IncRNA-UCA1 promoter activity was detected by luciferase assay $(*<<0.05 ; n=3)$. (B) Bladder cancer cells were transfected with $\mathrm{C} / \mathrm{EBP} \alpha$ binding site deleted lncRNAUCA1 promoter constructs. IncRNA-UCA1 promoter activity was detected by luciferase assay $\left({ }^{*} \mathrm{P}<0.05 ; \mathrm{n}=3\right)$.

assay. The results indicated that $\mathrm{C} / \mathrm{EBP} \alpha$ siRNA decreased the viability of the BLZ-211 cells (Fig. 6A). In order to validate whether the decreased cell viability via the reduction of $\mathrm{C} / \mathrm{EBP} \alpha$ is mediated through the reduction of IncRNAUCA1, we used BLS-211 cells as control cells since they lack lncRNA-UCA1 expression. There was no obvious change in BLS-211 cell viability (Fig. 6B) following $\mathrm{C} / \mathrm{EBP} \alpha$ silencing. We also observed a significant promotion in apoptosis of the BLZ-211 cells induced by $\mathrm{C} / \mathrm{EBP} \alpha$ siRNA while no change was displayed in the BLS-211 cells (Fig. 6C and D). These results suggest that lncRNA-UCA1 is activated by C/EBP $\alpha$, and thus, is involved in the regulation of bladder cancer cell growth and apoptosis.

\section{Discussion}

Several recent reports have shown that lncRNAs play important roles in many physiological and pathological processes, particularly in carcinogenesis. lncRNAs have oncogenic or tumor-suppressive effects, and their dysregulation is found throughout the entire processes of generation, development and metastasis of cancers. Blocking the expression of oncogenic lncRNAs or activating the expression of tumor-suppressor lncRNAs could reverse the invasive and metastatic features of human cancer cells, indicating the potential versatility of IncRNAs as prognostic biomarkers and therapeutic targets for a diverse group of cancers $(18,19)$. Among these lncRNAs, 


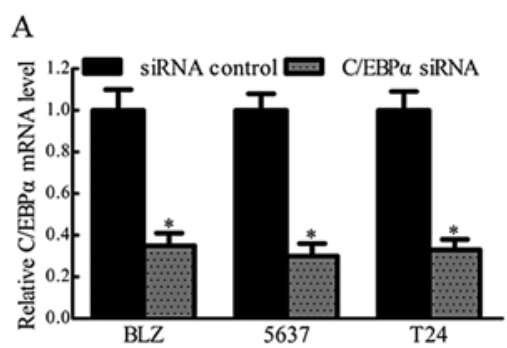

$\mathrm{B}$

C
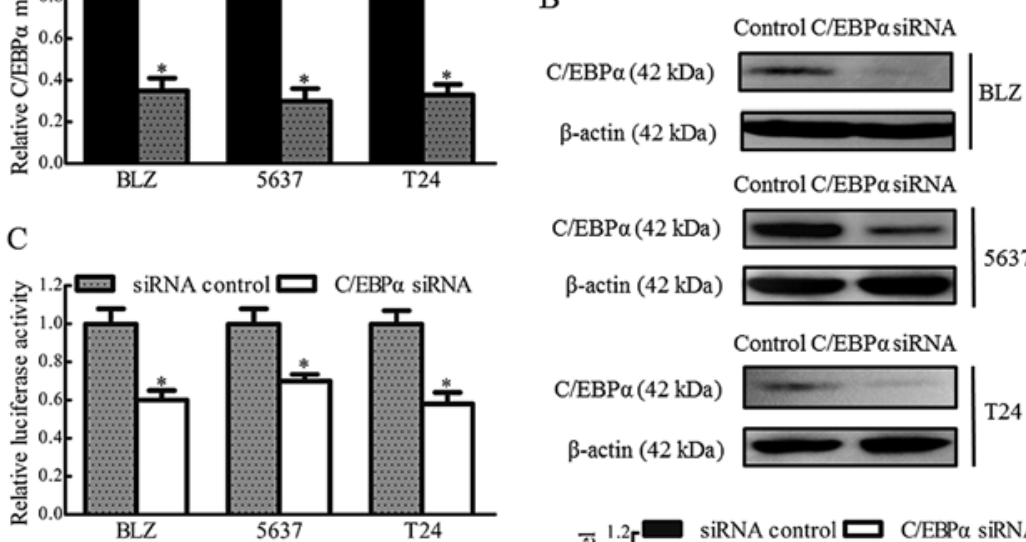

$\mathrm{C} / \mathrm{EBP} \alpha(42 \mathrm{kDa})$

$\beta$-actin (42 kDa)
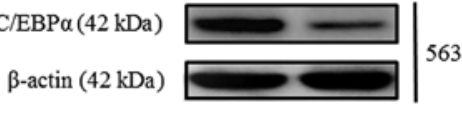
5637

$\mathrm{C} / \mathrm{EBP} \alpha(42 \mathrm{kDa})$

$\beta$-actin (42 kDa)

Control C/EBP $\alpha$ siRNA
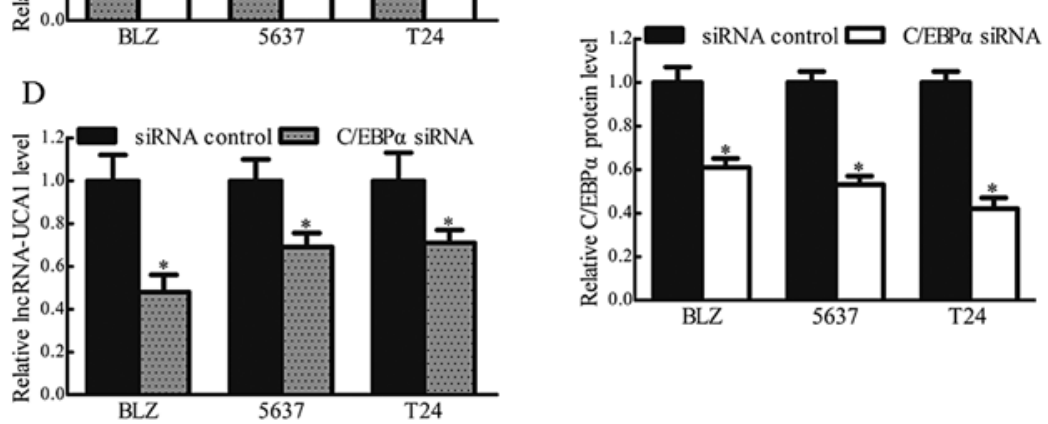

Figure 4. C/EBP $\alpha$ binds to the core promoter regions of lncRNA-UCA1 and regulates its expression. (A and B) Knockdown efficiency of $\mathrm{C} / \mathrm{EBP} \alpha$ siRNA was determined by real-time PCR and western blotting. $\beta$-actin was used as the internal control ( $\mathrm{P}<0.05$; $\mathrm{n}=3)$. (C and $\mathrm{D}) \mathrm{The}$ effects of $\mathrm{C} / \mathrm{EBP} \alpha$ silencing on the lncRNA-UCA1 promoter activity and expression were detected by luciferase assay and real-time $\mathrm{PCR}$. $\beta$-actin was used as the internal control ( $\mathrm{P}<0.05$; $\mathrm{n}=3$ ).

A
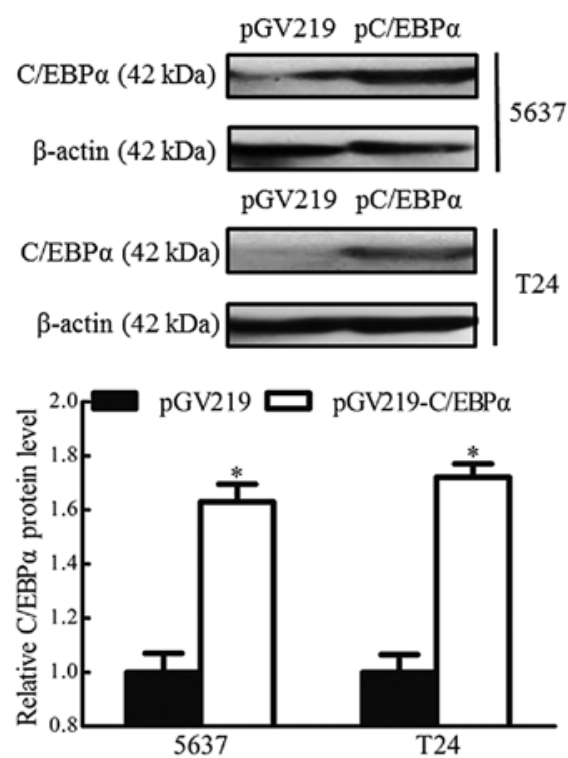

B

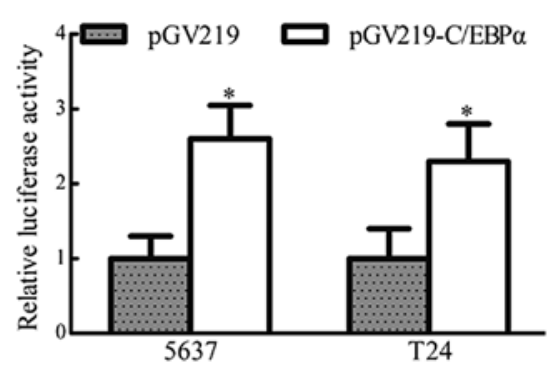

$\mathrm{C}$

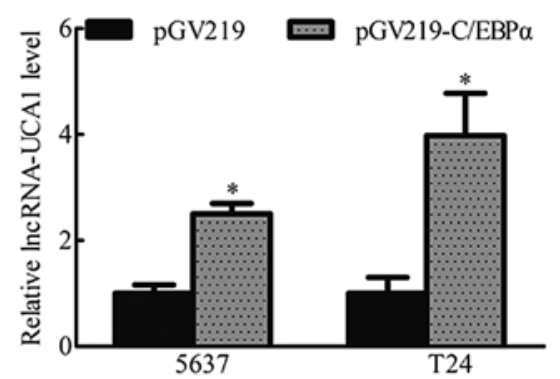

Figure 5. C/EBP $\alpha$ upregulates IncRNA-UCA1 expression. (A) Overexpression efficiency of the C/EBP $\alpha$ expression vector was detected by western blotting. $\beta$-actin was used as the internal control ("P<0.05; $\mathrm{n}=3$ ). (B and C) The effects of $\mathrm{C} / \mathrm{EBP} \alpha$ overexpression on the lncRNA-UCA1 promoter activity and expression were detected by luciferase assay and real-time PCR. $\beta$-actin was used as the internal control $\left({ }^{*} \mathrm{P}<0.05 ; \mathrm{n}=3\right)$.

lncRNA-UCA1 particularly aroused our attention due to its significant upregulation in bladder cancer, which is closely associated with the proliferation, metastasis and drug resistance of bladder cancer cells. A recent study showed that IncRNA-
UCA1 in urinary sediments is a highly specific and sensitive biomarker for the diagnosis and prognosis of bladder cancer (9). Consequently, the abnormal upregulation of lncRNAUCA1 may contribute to the development and metastasis of 
A

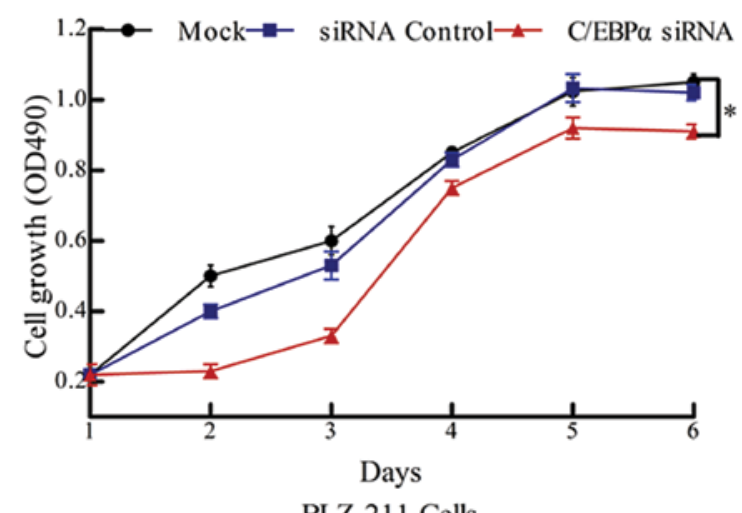

BLZ-211 Cells

$\mathrm{C}$

BLZ-211 cells
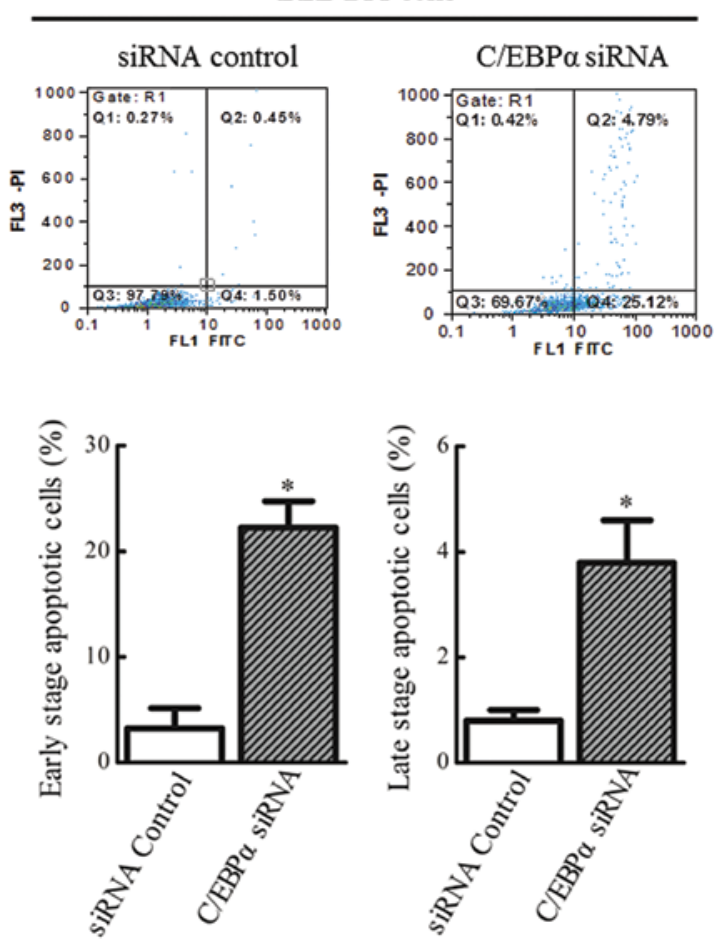

B

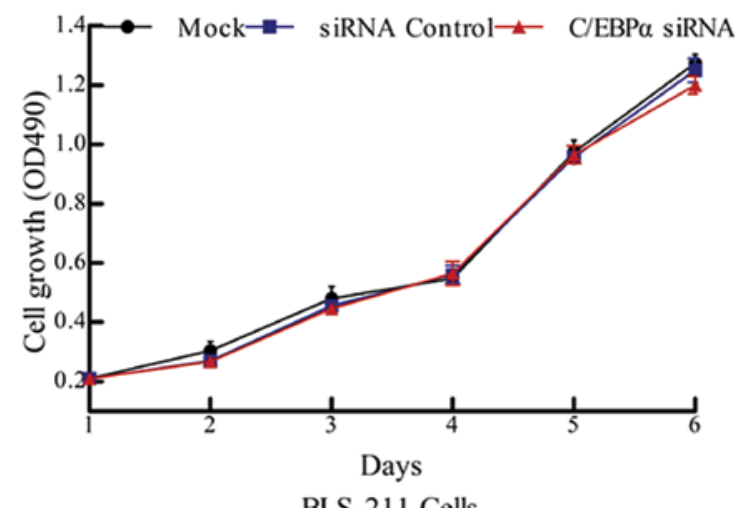

BLS-211 Cells

$\mathrm{D}$

BLS-211 cells

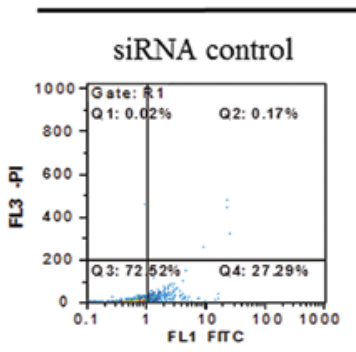

C/EBP $\alpha$ siRNA
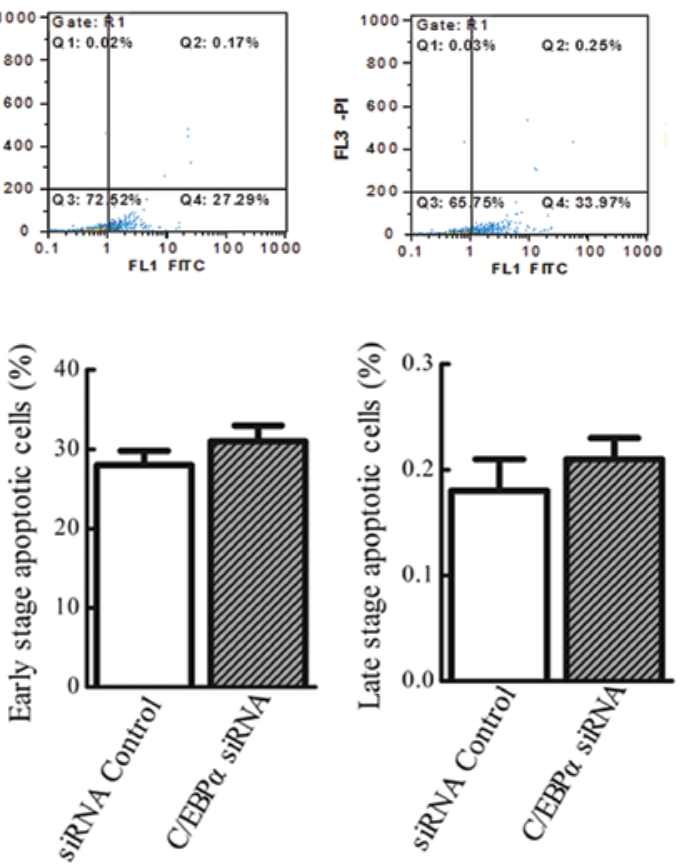

Figure 6. $\mathrm{C} / \mathrm{EBP} \alpha$ regulates lncRNA-UCA1 expression to increase cell viability and reduce cell apoptosis. (A and B) Bladder cancer cells were transfected with $\mathrm{C} / \mathrm{EBP} \alpha$ siRNA, and the cell viability was detected by MTT assay ( $\mathrm{P}<0.05 ; \mathrm{n}=3$ ). (C and D) Bladder cancer cells were transfected with $\mathrm{C} / \mathrm{EBP} \alpha$ siRNA, and apoptosis was detected by flow cytometry ( $\mathrm{P}<0.05 ; \mathrm{n}=3$ )

human bladder carcinoma, while the underlying molecular mechanism for lncRNA-UCA1 dysregulation remains to be elucidated. Therefore, through bioinformatic analysis, we discovered that there are several potential transcription factor binding sites in the IncRNA-UCA1 core promoter, which indicate that these transcription factors may be involved in the regulation of IncRNA-UCA1 expression.

Highly upregulated in liver cancer (HULC) is an lncRNA uniquely overexpressed in liver cancer and plays a pivotal role in hepatocarcinogenesis (20). A cAMP responsive element binding protein (CREB) binding site is found in the HULC promoter (21). Bound and activated by p53 at the large intergenic non-coding RNA-p21 (lincRNA-p21) promoter region, lincRNA-p21 serves as a transcription repressor in the p53 pathway (22). These data are typical examples of the regulation of IncRNA activity by common transcription factors via binding with the promoters of lncRNAs. In the present study, we demonstrated that $\mathrm{C} / \mathrm{EBP} \alpha$ binds with the IncRNAUCA1 core promoter (Fig. 2A and B). We also showed that $\mathrm{C} / \mathrm{EBP} \alpha$ modulates lncRNA-UCA1 expression (Figs. 4D and 5C). Our future research, extensive and more concrete, will focus on exploring other regulatory factors that influence lncRNA-UCA1 expression in bladder cancer, including DNA methylation, histone modification and specific microRNA expression.

Similar to other common transcription factors, $\mathrm{C} / \mathrm{EBP} \alpha$ is a ubiquitously expressed transcription factor that activates the transcription of various genes by interacting with the $\mathrm{C} / \mathrm{EBP} \alpha$ binding motif in respective promoters. A recent study reported a $\mathrm{C} 1797 \mathrm{G}$ polymorphism in the protein coding gene of murine double minute 2 (MDM2) promoter of bladder cancer, and that the $C$ to $G$ substitution enhances the affinity of $C / E B P \alpha$ to 
this region in the MDM2 promoter (23). Intriguingly, we also found that the $\mathrm{C} / \mathrm{EBP} \alpha$ binding motif contains a base transversion (A231G) in T24 cells, and ChIP results showed that the brightness of the $\mathrm{C} / \mathrm{EBP} \alpha$ bands in $\mathrm{T} 24$ cells was significantly higher than that in the other two cell lines, which may be attributed to the base mutation in the $\mathrm{C} / \mathrm{EBP} \alpha$ binding motif (Fig. 2B and C) and this specific point mutation can affect the binding affinity of $\mathrm{C} / \mathrm{EBP} \alpha$ to the IncRNA-UCA1 promoter. Although our results indicated that the mutation (A231G) increased the transcriptional activity of IncRNA-UCA1, how it regulates IncRNA-UCA1 RNA levels remains unclear and warrants further research.

Our previous study showed that silencing of lncRNAUCA1 expression in BLZ-211 cells resulted in the decrease in the expression of several cell cycle-associated genes, particularly encoded p300 and its co-activator CREB. Furthermore, IncRNA-UCA1 was found to regulate cell proliferation by activating CREB protein through the PI3-K/AKT signaling pathway (11). The PI3-K/AKT signaling pathway has been proven to play a critical role in cellular growth and apoptosis, and also serves as a therapeutic target in human cancers. In the present study, we confirmed that $\mathrm{C} / \mathrm{EBP} \alpha$ regulates lncRNAUCA1 expression to increase cell viability and reduce cell apoptosis in vitro. Therefore, it is possible that the regulation of lncRNA-UCA1 expression by $\mathrm{C} / \mathrm{EBP} \alpha$ in manipulating cell viability and apoptosis may also be conducted via the PI3-K/AKT signaling pathway, and this hypothesis will be confirmed in forthcoming studies

In conclusion, our research reveals a novel mechanism for the upregulation of IncRNA-UCA1 expression in bladder cancer cells. These findings demonstrate that transcription factor $\mathrm{C} / \mathrm{EBP} \alpha$ is bound to the binding site in the core promoter of lncRNA-UCA1, leading to the activation of lncRNA-UCA1 transcription. The transcriptional activation of lncRNA-UCA1 by $\mathrm{C} / \mathrm{EBP} \alpha$ also contributes to the increased viability and decreased apoptosis of bladder cancer cells. Clinical studies aimed at assessing the association between IncRNA-UCA1 transcriptional regulators and pathological parameters of bladder carcinoma tissues are needed for confirming our results and for exploring the potential clinical application of lncRNA-UCA1 as a therapeutic target for bladder cancer.

\section{Acknowledgements}

The present study was supported by grants (nos. 81171970 , 81072104 and 30370660) from the National Natural Science Foundation of China.

\section{References}

1. Siegel R, Naishadham D and Jemal A: Cancer statistics, 2013. CA Cancer J Clin 63: 11-30, 2013.

2. Jacobs BL, Lee CT and Montie JE: Bladder cancer in 2010: how far have we come? CA Cancer J Clin 60: 244-272, 2010.
3. Kamat AM, Hegarty PK, Gee JR, et al: ICUD-EAU International Consultation on Bladder Sancer 2012: Screening, diagnosis, and molecular markers. Eur Urol 63: 4-15, 2013.

4. Orom UA, Derrien T, Beringer M, et al: Long noncoding RNAs with enhancer-like function in human cells. Cell 143: 46-58, 2010.

5. Guttman M, Donaghey J, Carey BW, et al: lincRNAs act in the circuitry controlling pluripotency and differentiation. Nature 477: 295-300, 2011.

6. Lee JT: Epigenetic regulation by long noncoding RNAs. Science 338: 1435-1439, 2012

7. Taft RJ, Pang KC, Mercer TR, Dinger M and Mattick JS: Non-coding RNAs: regulators of disease. J Pathol 220: 126-139, 2010.

8. Gutschner T and Diederichs S: The hallmarks of cancer: a long non-coding RNA point of view. RNA Biol 9: 703-719, 2012.

9. Wang XS, Zhang Z, Wang HC, et al: Rapid identification of UCA1 as a very sensitive and specific unique marker for human bladder carcinoma. Clin Cancer Res 12: 4851-4858, 2006.

10. Wang F, Li X, Xie X, Zhao L and Chen W: UCA1, a non-proteincoding RNA up-regulated in bladder carcinoma and embryo, influencing cell growth and promoting invasion. FEBS Lett 582: 1919-1927, 2008

11. Yang C, Li X, Wang Y, Zhao L and Chen W: Long non-coding RNA UCA1 regulated cell cycle distribution via CREB through PI3-K dependent pathway in bladder carcinoma cells. Gene 496: 8-16, 2012.

12. Wang Y, Chen W, Yang C, et al: Long non-coding RNA UCA1a (CUDR) promotes proliferation and tumorigenesis of bladder cancer. Int J Oncol 41: 276-284, 2012.

13. Chen G, Wang Z, Wang D, et al: LncRNADisease: a database for long-non-coding RNA-associated diseases. Nucleic Acids Res 41: D983-D986, 2013.

14. Guttman M, Amit I, Garber M, et al: Chromatin signature reveals over a thousand highly conserved large non-coding RNAs in mammals. Nature 458: 223-227, 2009.

15. Yang JH, Li JH, Jiang S, Zhou H and Qu LH: ChIPBase: a database for decoding the transcriptional regulation of long non-coding RNA and microRNA genes from ChIP-Seq data. Nucleic Acids Res 41: D177-D187, 2013.

16. Yang YC, Li X and Chen W: Characterization of genes associated with different phenotypes of human bladder cancer cells. Acta Biochim Biophys Sin 38: 602-610, 2006.

17. $\mathrm{Wu} \mathrm{W}$, Zhang $\mathrm{S}$, Li X, et al: Ets-2 regulates cell apoptosis via the Akt pathway, through the regulation of urothelial cancer associated 1, a long non-coding RNA, in bladder cancer cells. PLoS One 8: e73920, 2013.

18. Gupta RA, Shah N, Wang KC, et al: Long non-coding RNA HOTAIR reprograms chromatin state to promote cancer metastasis. Nature 464: 1071-1076, 2010.

19. Brunner AL, Beck AH, Edris B, et al: Transcriptional profiling of long non-coding RNAs and novel transcribed regions across a diverse panel of archived human cancers. Genome Biol 13: R75, 2012.

20. Panzitt K, Tschernatsch MM, Guelly C, et al: Characterization of HULC, a novel gene with striking up-regulation in hepatocellular carcinoma, as noncoding RNA. Gastroenterology 132: 330-342, 2007.

21. Wang J, Liu $\mathrm{X}, \mathrm{Wu} \mathrm{H}$, et al: CREB up-regulates long non-coding RNA, HULC expression through interaction with microRNA372 in liver cancer. Nucleic Acids Res 38: 5366-5383, 2010.

22. Huarte M, Guttman M, Feldser D, et al: A large intergenic noncoding RNA induced by p53 mediates global gene repression in the p53 response. Cell 142: 409-419, 2010.

23. Wang M, Zhang $\mathrm{Z}$, Zhu $\mathrm{H}$, et al: A novel functional polymorphism $\mathrm{C} 1797 \mathrm{G}$ in the $M D M 2$ promoter is associated with risk of bladder cancer in a Chinese population. Clin Cancer Res 14: 3633-3640, 2008. 